\title{
The Effectiveness of Error Analysis in Translation Classes. A Pilot Study
}

\author{
Diana Presada and Mihaela Badea \\ University of Ploiesti
}

Received: 24 April 2013 / Accepted: 23 July 2013

ISSN: $1697-7467$

\begin{abstract}
The purpose of our pilot study is to demonstrate the effectiveness of error analysis within the translation classes attended by students in Philology at Petroleum - Gas University of Ploiesti. As it represents an important classroom procedure that allows teachers to identify the degree to which students master the target language (English), it has proved its major role in improving students' linguistic performance. The study has been developed on the basis of a theoretical framework (contrastive and error analysis) and an investigation of students' achievements as regards their translation skills, the main aim being to identify the most frequent types of errors and their causes. Our findings will constitute a data base necessary to conceive a more effective teaching and learning process that focuses not only on translation classes, but also on the acquisition of English as a foreign language in general.

Key words: error analysis, contrastive analysis, translation, causes of error production
\end{abstract}

\section{La eficacia del análisis de errores dentro de las clases de traducción. Un estudio piloto}

RESUMEN: El propósito de este estudio piloto es demostrar la eficacia del análisis de errores dentro de las clases de traducción de los estudiantes de Filología de Petroleum - Gas University of Ploiesti. Como representa un procedimiento de aula importante, que permite a los maestros identificar el grado en que los estudiantes dominan el idioma de destino (inglés), tiene un importante papel en la mejora del rendimiento lingüístico de los estudiantes. El estudio se desarrolló sobre la base de un marco teórico (análisis de contraste y análisis de errores) y una investigación de los logros de los estudiantes en cuanto a sus habilidades de traducción asumiendo como objetivo principal identificar los tipos más frecuentes de errores y sus causas. Los resultados constituyen una base de datos necesaria para concebir un proceso más eficaz de enseñanza y aprendizaje que se centra no sólo en las clases de traducción, sino también en la adquisición del inglés como lengua extranjera en general.

Palabras clave: análisis de errores, análisis de contraste, traducción, las causas de la producción de errores

\section{INTRODUCTION}

As practising teachers, we have noticed that error analysis (EA) can be a very effective tool for improving students' English language acquisition and skills. Owing to the fact that the teaching and learning process also focuses on the development of students' translation abilities, the aim of our paper is to show the usefulness of the error analysis method in approaching translation classes. Furthermore, we have taken a particular interest in such a 
research topic because the Philology students of our university sit a translation test which is an important part of their graduation examination.

As shown by Kim (2013) various methods of assessing translations, which are commonly used in European, Canadian and Australian academic institutions, have proved to be valid and reliable, these methods consisting in error analysis proper or in its combination with the holistic method. However, in our country there are not enough studies dedicated to Romanian learners of English from the perspective of error analysis, that is why our enterprise benefitted from the valuable contributions of a wide variety of researchers to error analysis, such as: Dušková (1969), who examined Czech learners of English, Light and Warshawsky (1974), who studied errors of Russian learners of English, Guilford (1998), who investigated typical errors produced by French learners, Vassileva (1998), who explored the linguistic problems of German, French, Russian and Bulgarian learners, Yang and Huang (2004), who studied specific difficulties of Chinese learners in acquiring English etc.

Our approach is in line with the existing direction within the field of Applied Linguistics whose main tenets belong to contrastive analysis (CA). In "Linguistics across Culture", Lado, the founder of the above mentioned movement, pointed out that second language acquisition implies two mechanisms, namely, positive and negative linguistic transfer. Thus, in his view, elements that are similar to one's language are simple for the student (positive transfer), whereas the elements that are different tend to be perceived as difficult (1957:2), causing interferences as a source of errors (negative transfer). Starting from the same theory, some researchers state that similarities between languages favor positive transfer, as is the case of the German learners of English, while, we may add, dissimilarities engender a negative transfer, as is the case of the Romanian learners of English.

Within a Behaviourist framework, Lado's Contrastive Analysis Hypothesis (CAH), which was both a theory and a method, was highly influential in the 60 s and early 70 s leading to the development of language teaching and research. However, this point of view is limited as teaching a foreign language cannot be reduced to a simple process implying similarities and differences seen as a way to predict learning difficulties. Moreover, language acquisition should not be confused with an automatic transferring of rules from the source language to the target one.

Refining Lado's viewstands, Wardhaugh referred to, in a paper published in 1970, the existence of two versions of CAH, the strong one, according to which the majority of L2 errors are based on a negative transfer, and the weak one that explains errors as a result of interference between L1 and L2. Indeed, the first version was highly criticized and later abandoned, while the weak or moderate version has proved its benefits in teaching English being one of the most frequent methods adopted by English teachers even nowadays.

CA represented a starting point for developing error analysis whose purpose was to identify and examine the errors made by students. Their role in and significance for the teaching of English was emphasized by Corder (1987) in the following terms:

The first to the teacher in that they tell him, if he undertakes a systematic analysis, how far towards the goal the learner has progressed, and consequently, what remains for him to learn. Second, they provide to the researcher evidence of how language is learned or acquired, what strategies or procedures the learner is employing in his discovery of the language. Thirdly (and in a sense this is their most important aspect) they are indispensible to the learner himself, because we can regard the making of errors as a device the learner uses in order to learn. 
Viewed from this angle, the major contribution of error analysis resided in shifting the stress from the pedagogical orientation to the scientific one and in seeing error production not only as a result of linguistic transfer, but also as an outcome determined by a variety of factors.

Richards enlarged Corder's theory, adding to interlanguage/interference errors a new category that can be identified in the learning activity of a foreign language, that is, intralingual and developmental errors belonging to the acquisition process. While the objective of the CA was to explain the former category, EA aimed at analyzing and understanding the causes leading to the occurrence of the latter one. As not all errors that students make could be explained by CA, Richards' influential ideas aroused the researchers' interest in EA.

The two types of errors connected with foreign language acquisition, inter and intralingual, formed the basis of the present approach to error production. Besides these categories of errors, we have discovered other perspectives of classifying them in recent works that are also beneficial for the purpose of our research. A significant distinction between expressive and receptive errors was conceived by Hussain et al. (2013:830) starting from language skills, namely writing and speaking (productive skills) and speaking and listening (receptive skills). We consider that the term "expressive" completes the above mentioned distinction because it also reflects the subjective part of human personality. The translation process should be understood not only as acquisition on a cognitive level, but also as a result of several subjective factors which involve imagination, talent and receptivity that cannot be objectively quantified. That is why, in our opinion, the role of the translator should not be reduced to an accurately functioning translation machine, but to a complex "text producer in the target culture" (Nord, 2005:13).

Our research tackles the concept of "error" as different from "mistake", the two terms being defined by Hubbard et al. (1991:134) as follows: while genuine errors are produced by students' insufficient knowledge about L2 or "by incorrect hypotheses about it", mistakes are due to "temporary lapses of memory, confusion, slips of the tongue and so on".

Although an automatic method for the classification and interpretation of errors could have been more effective due to the fact that "human error classification is a difficult and time consuming task" (Popović, 2011: 59), we preferred the classical approach as we regarded translation as an expressive act.

\section{Methodology}

\subsection{Objective}

The aims of the present pilot study was to identify the errors made by foreign language students during their translation classes, and establish the causes of error production in order to improve students' translation skills. Such a purpose was achieved by answering the following research questions that guided our analysis:

1. What kind of linguistic transfer is dominant: the negative or positive transfer?

2. What are the most frequent types of errors that students usually make in their translation tasks?

3. What other causes determine the production of errors? 


\subsection{Participants}

The people involved in our pilot research are 40 Philology students that study English as part of an undergraduate academic programme at the Petroleum Gas University of Ploiesti. They are enrolled in the third year of study and are trained for both teaching and translation careers. As translation tasks constitute a major component of the English practical courses that students attend, their translation skills are tested semesterly and at the completion of their studies on the occasion of the graduation examination, which includes the translation of various texts from Romanian into English and vice versa.

\subsection{Procedure}

In order to find answers to the research questions mentioned above, we analysed the written tests of the students involved in the research, applying the error manual of Dagneaux et al. (1996), which was altered in accordance with the purpose of our paper.

The types of errors that we identified, together with their codes, are indicated in the table below:

Table 1. Error codes (adapted from Dagneaux et al., 1996)

\begin{tabular}{cl}
\hline Error code & Type of error \\
\hline GSO & grammar - subject omission \\
\hline GCA & grammar - continuous aspect \\
\hline GVT & grammar - verb tense \\
\hline GST & grammar - sequence of tenses \\
\hline GIF & grammar - conditional clauses \\
\hline WO & word order \\
\hline GUN & grammar - uncountable nouns \\
\hline GP & grammar - propositions \\
\hline GNEG & grammar - double negation \\
\hline GIA & grammar - indefinite articles \\
\hline GDA & grammar - definite articles \\
\hline WOM & word omissions \\
\hline VLC & vocabulary - lexical confusion \\
\hline
\end{tabular}

Starting from the errors classified according to the taxonomy above, we were able to determine the causes leading to their production. This research allowed us to identify the difficulties that students experience during the learning process and provided us with the framework for a well-planned teaching programme to be adopted in the future, as part of a remedial teaching stage.

It should be noted that the category of mistakes including memory lapses, distractions, hesitations and other psychological factors did not constitute the purpose of our analysis on the grounds that, in comparison with errors, they do not play an important role in the teaching and learning process. 


\section{Data analysis}

Taking into consideration a quantitative criterion, we found that the vast majority of the errors made by students in translation classes are caused by negative linguistic transfer, that is, a high level of interference between the lexical and grammatical structures of the native tongue and the ones of the target language. The results of the quantitative analysis are shown in the table below:

Table 2. Inventory of errors in students' samples

\begin{tabular}{rlccc}
\hline & & & Number of & \\
& & Error code & errors & Percentage \\
\hline 1 & subject omission & GSO & 378 & 20.03 \\
\hline 2 & misuse of the continuous aspect & GCA & 352 & 18.65 \\
\hline 3 & confusion between present perfect and past tense & GVT & 326 & 17.28 \\
\hline 4 & sequence of tenses & GST & 275 & 14.57 \\
\hline 5 & if clauses & GIF & 98 & 5.19 \\
\hline 6 & word order & WO & 96 & 5.09 \\
\hline 7 & misuse of uncountable nouns & GUN & 78 & 4.13 \\
\hline 8 & misuse of prepositions & GP & 74 & 3.92 \\
\hline 9 & double negation & GNEG & 71 & 3.76 \\
\hline 10 & omission of indefinite articles & GIA & 39 & 2.07 \\
\hline 11 & misuse of definite articles & GDA & 34 & 1.80 \\
\hline 12 & omissions & WOM & 34 & 1.80 \\
\hline 13 & lexical confusion & VLC & 32 & 1.70 \\
\hline & Total number of errors & & 1887 & 100.00 \\
\hline
\end{tabular}

It is noteworthy that the most frequent interlanguage errors include the omission of the subject $(20.03 \%)$ and the incorrect use of the indicative mood tenses (14.57\%) in subordinate clauses. As to the former category of errors, let us mention that the omission of the subject in independent declarative sentences is rare, whereas the cases in which the subject is left out in subordinate clauses are very frequent. For instance, we found numerous correct sentences like "It is a fine day today, isn't it?", "The weather is fine as usual in this part of the country", in contrast to "When he saw his girlfriend approaching the garden, jumped with joy" or "She did not enter the elegantly decorated ballroom because was not able to make the steps of the Viennese waltz correctly", etc. As far as the latter category of errors is concerned, many examples show that students do not master the appropriate usage of tenses in indirect speech, such as "He said that he is an engineer and works for a multinational company based in Saudi Arabia" or "He said that his name is Eric and that he comes from nowhere". The errors mentioned above can be explained by the influence of 
the Romanian language where both simple and complex sentences do not need the presence of the subject, as in Romanian the ending of the verb indicates the person. The fact that the verb is an inflectional part of speech shows students' tendency to skip using the subject in subordinate clauses. The misuse of the tenses in indirect speech derives from the characteristic of Romanian which does not have fixed rules concerning the sequence of tenses in subordinate clauses that follow past tenses in the main clauses. In a complex sentence like: "Am spus că Tom este la şcoală" Romanian native speakers use the present ("is") after the past tense ("said"), in contrast with English, which, in most cases, requires a past form in the subordinate clause. ("I said that Tom was at school.")

Another series of errors resulting from the negative transfer of linguistic structures from L1 to L2 should also be taken into account although the percentages are not as high as the first two categories that we have already analyzed. The most frequent errors refer to the incorrect use of the tenses in if-clauses, especially type I (5.19\%), wrong word order $(5.09 \%)$, misuse of uncountable nouns $(4.13 \%)$, misuse of prepositions $(3.92 \%)$, double negation $(3.76 \%)$, omission of the indefinite article $(2.07 \%)$ and misuse of the definite article $(1.80 \%)$. For instance, we found sentences like "If the weather will be fine I'll go to the mountains to contemplate the beauty of the landscape", "I like very much English people", "The money are on the table in the corner of the dark room", "He is the most intelligent from all the boys she has encountered in her life", "You'll get fat unless you don't stop eating all that crap food that your wife is preparing for you", or "The dogs are the most friendly animals on earth".

The errors listed above are due to the Romanian grammatical patterns and linguistic rules which function differently from the ones of English. One of these discrepancies is obvious in the case of real conditions which in Romanian are expressed by means of both future and present tenses. Another dissimilarity concerns the word order, the Romanian language being more flexible than English, and thus leading to the production of inaccurate structures in L2. To take one example, in Romanian there is no difference in meaning between "Îmi place engleza foarte mult" and "Îmi place foarte mult engleza", whereas in English the direct object follows the verb. ("I like English very much."). As regards the wrong use of uncountable nouns, a source of errors stems from the fact that in Romanian some nouns are countable, while in English the same nouns are singular uncountable with no plurals (money, information, luggage etc.) or plural uncountable with no singular forms (scissors, overalls, pyjamas, etc.). With respect to double negation errors, these originate in the flexibility of Romanian which commonly allows the use of multiple negations within the same sentence ("Nu am văzut pe nimeni nicăieri" = "I haven't seen anyone anywhere."). The other categories of errors shown above involve the lack of correspondence between the use of definite and indefinite articles or prepositional phrases in L1 and L2 ("El este $\varnothing$ profesor = He is a teacher", "A intrat în cameră = He entered $\varnothing$ the room").

Apart from the types of errors that we have discussed up to now, there are two instances which need special attention, namely the misuse of the continuous aspect $(18.65 \%)$ and the confusion between the present perfect and past tenses (17.28\%). For example, we encountered sentences like "He watches his favorite series on TV now instead of taking care of the baby.", "He has passed by yesterday to check the state of your house". These errors can be considered a distinct category because their production is a consequence of the fact that the concept of aspect does not exist in the Romanian language. For this reason, 
students cannot make a clear distinction between, for instance, "I often read books" and "I am reading a book now", or between "I have just finished the letter" and "I finished the letter yesterday". As, in general, the students' unique guiding principle in such cases is the presence of a specific adverb of frequency in the sentence, they do not manage to internalize the concept of progressive or perfective aspect, which results in sentences like "He was often reading books when he was a high school student", "I am writing letters since yesterday" or "He has been watching a film for an hour yesterday".

All the errors that we have analyzed so far reveal that in the case of poor performance in English, the lexical and grammatical structures of L1 influence the generation of errors in L2 to a great extent. Nevertheless, we discovered various instances of omissions and lexical confusions which are linked to a higher degree of language acquisition. Such examples of errors are: "Michael considers Victor as his best friend" instead of "Michael considers Victor his best friend", "I don't have time to finish my homework today" instead of "I haven't time to finish my homework today" (the second structure being used for particular occasions), "Helen has got black hair" instead of the literary construction "Helen has black hair", "You needn't help your friends if they don't ask for it" instead of "You don't need/have to help your friends if they don't ask for it", "Paper is made of wood" instead of "Paper is made from wood" . As the percentages of such types of errors are very low (1.80\% and $1.70 \%)$, we consider that the basic causes of error production in the translation exercises under discussion were determined by the students' failure to consolidate the linguistic structures of the target language.

As to the intralingual and developmental errors, they can be divided into two categories. The first one comprises the errors that are generally caused by students' tendency to hypercorrectness or overgeneralization, such as the redundant use of the ending "s" and the presence of the double subject or object: "She does not studies French at school as she hates it", "He can speaks Italian too, even if he only spent some months in Rome", "My little sister she answered the phone", "The house which I bought it was situated in the outskirts of the city I was born". In comparison with the errors occurring as a result of the negative linguistic transfer, these are less numerous and not as various as the previous type.

The second category, which is the most comprehensive one, includes the errors that are generally determined by the superficial acquisition of the target language. The examples illustrating it are various, ranging from wrong verbal structures, confusion between stative and dynamic verbs, misuse of the infinitive or gerund to misplaced negation in compound verbs. As such type of errors are numerous we selected only the following: "Did you went to church yesterday, "He must had been ill", "I am knowing the truth now", "He left without to say goodbye.", "She went there for meeting her friends.", and "She should have not answered that question".

If the errors shown so far imply the linguistic relation between Romanian and English, either in the form of a positive or negative transfer, there are other causes of errors that are manifest in the tests of the students who study more than one foreign language. We have often noticed that students in French tend to produce more errors than the ones specializing in Romanian and English. This can be explained by a higher degree of interference among languages, students also acquiring lexical and grammatical patters specific to French, which, in its turn, becomes a source of errors. Such examples are illustrated by adding the "-s" ending to the English adjective according to the agreement between adjectives and nouns 
common in French ("They have discussed importants things.") and by adding the "-e" ending specific to the first group of singular regular verbs in French to the first or third person singular in English ("I demande that you do your daily duties.").

It is true that all types of errors that we discussed above constitute the base of error production, but there are also minor cases that should be taken into consideration too, such as spelling errors or errors due to students' lack of attention or tiredness, a phenomenon which does not plead for students' weak acquisition of L2, but for uncontrolled external or psychological factors.

\section{Conclusions}

The analysis of the students' translation samples showed that a large number of the errors they produced are the result of both negative and positive linguistic transfer. Nevertheless, it is worthwhile mentioning that the first type of transfer is predominant, demonstrating that the students that took part in the research still resort to the linguistic system of their native language as a mechanism of L2 acquisition. As a group of researchers from the University La Rioja emphasized in a study conducted in 2005, "The learners' mother tongue serves as the linguistic scaffolding upon which they develop their L2 competence." (Llach et al., 2005:3). Although this point of view explains the normal process of foreign language acquisition, our research revealed a dysfunction of the learning process in our university, which is reflected in the students' weak level of the target language, raising the question of the causes leading to this state of affairs.

Starting from our observations during the present study and our regular teaching activity, we may state that a possible explanation lies in the pedagogical approach itself. It is a fact that most translation classes are considered by students to be monotonous because teachers make excessive use of old-fashioned methods, especially of the "triadic dialog" consisting in initiation, response and evaluation (Chin, 2006:1315), which do not enable learners to perform in an effective way. As the author puts it in an article on classroom interaction, this technique "is typical of traditional teaching" and is "often perceived to have restrictive effects on students' thinking as students' responses remain brief and teacher-framed (Chin, 2006:1315). In other words, such classes privilege "a command style" according to which "the teacher makes all decisions, and the learner complies with the teacher's directions", (Goldberger et al., 2012: 270). As the teacher is in control of the whole process and offers the model of the best linguistic solutions linked to the translation tasks, most traditional translation classes fail to truly engage students in the learning activities. That is why we fully agree with Harmer (2005:56) who defines successful classroom practice as follows: "The measure of a good lesson is the student activity taking place, not the performance of the teacher." As he also points out, in a learner-centred class, "it is students' needs which should drive the syllabus, not some imposed list; it is the students' learning experiences and their responses to them which should be at the heart of a language course." (Harmer, 2005:56). We believe that a radical change in teachers' view on classroom instruction based on the principles of active learning will help students improve their knowledge of English substantially. 
Another factor that could be taken into consideration is the teachers' compliance with "conformity and standardisation" in point of teaching strategies, which "contends that the curriculum (and teaching) can be 'teacher-proofed' through the provision of re-usable materials and standardised structures and activities." (Lupton, 2011: 2). As teaching translation still consists in transmitting knowledge from the teacher to students, the focus is not on how to teach but on what to teach, the content prevailing over the novelty and variety of the classroom strategies that task-based learning requires. Consequently, students lack the necessary conditions to learn by themselves, and come to develop a negative perception of translation classes, disliking the passive role they are compelled to adopt during the teaching and learning activities.

Moreover, the development of the skills specific to translations tasks, i.e. work with the dictionary, seems to be ignored. During our research we noticed that, relying on the teachers' solutions to translation problems, most students avoid utilizing dictionaries to solve their translation tasks or, in case they do use them, the dictionaries are not adequate for a translation assignment (e.g. students make use of English-Romanian dictionaries instead of monolingual/learner's dictionaries, or general dictionaries for the translation of specialized texts). Needless to say that if students are not completely familiar with the techniques of using dictionaries properly, they face problems such as finding the right meaning of words, making the distinction between the connotative and denotative meanings of words, dealing with the "false friends" phenomenon or choosing the right synonym. Getting students to use comprehensive monolingual dictionaries effectively and regularly in translation classes will definitely reduce the production of errors helping them develop their knowledge in a complex way (by reading the definitions and explanations of the words, checking the pronunciation, spelling and register of a word, finding out grammatical information about a word, etc.)

Another cause that may explain the production of incorrect structures is that most students do not practise enough in translation classes because teachers generally tend to emphasize the theoretical side of language, privileging the learning of rules to the detriment of their practical use. In this way the teaching of translation implies a paradox: students have a high degree of competence, that is "perfect knowledge of grammatical rules, lexis and the sound system", and a low level of linguistic performance", which in Chomskyan terms means "what actually occurs in practice". Under such circumstances, their performance in point of translation can be regarded as "a faulty representation of competence" (Hubbard et al., 1991:133), or the speakers' "actual usage of the language"(Vizental, 2007:16) is weak in contrast with their good "knowledge of the code" (Vizental, 2007:16). As a consequence, the focus on the inductive approach to teaching translation skills proves the low level of L2 acquisition and the use of the native language as a perpetual support in doing translation exercises.

The number of developmental errors being low shows that they do not constitute a major cause of error production during translation classes. The same can be said about the other types of errors indicated by our analysis, but it is important to remember that they are "good evidence that progress is being made. Errors often show us that a student is experimenting with language, trying out ideas, taking risks, attempting to communicate, making progress." (Scrivener, 2005:298).

The aim of our research was not only to examine the production of errors in translation classes classifying them into categories, but also to identify their main causes starting from 
the premise that "the investigation of errors can serve two purposes, diagnostic (to in-point the problem) and prognostic (to make plans to solve a problem)", offering information to the teachers about "the learner's grasp of a language at any given point during the learning process" and indicating when the teachers have "to modify learning materials to meet the learners' problems." (Zawahreh, 2012:282). The present research proved to be fruitful for both learners and teachers as analyzing the causes of the errors produced by the Philology students in translation classes helped us sort out their problems and consequently improve the teaching and learning process itself. Therefore, we believe that conceiving a model of translation oriented text analysis based on clear criteria for "the classification of texts and guidelines for assessing the quality of a translation" (Nord, 2005:2) will help both teachers and students in such classes in order to achieve high standards in the process of translation.

\section{REFERENCES}

Chin, C. (2006). "Classroom Interaction in Science: Teacher questioning and feedback to students' responses", in International Journal of Science Education, 28, 11: 1315-46.

Corder, S.P. (1987). Error analysis and interlanguage. Oxford: Oxford University Press.

Dagneaux, E., Denness, S., Granger, S., \& Meunier, F. (1996). Error Tagging Manual Version 1.1. Louvain-la-Neuve: Centre for English Corpus Linguistics : Université Catholique de Louvain.

Dušková, L. (1969). “On sources of error in foreign language learning”, in International Review of Applied Linguistics (IRAL), 7, 1: 11-36.

Goldberger M., Ashworth, S. \& Byra, M. (2012). "Spectrum of Teaching Styles Retrospective", in Quest, 64, 4: 268-82.

Guilford, J. (1998). “English learner interlanguage: What's wrong with it?", in Anglophonia French Journal of English Studies, 4: 73-100.

Harmer, J. (2005). The Practice of English Language Teaching. Essex: Logman.

Hubbard, J., Jones, H., Thornton, B. Wheeler, R. (1991). A Training Course for TEFL. Oxford: Oxford University Press.

Hussain, Z., Hanif, M., Asif, S.I., Rehman, A.U. (2013). "An Error Analysis of L2 Writing at Higher Secondary Level in Multan, Pakistan", in Interdisciplinary Journal of Contemporary Research in Business, 4, 11: 828-44.

Kim, M. (2013). "Research on Translator and Interpreter Education", in C. Millan and F. Bartrina (eds.), The Routledge Handbook of Translation Studies. Abingdon: UK, 102-16.

Lado, R. (1957). Linguistics Across Cultures: Applied Linguistics for Language Teachers. Ann Arbor. MI. US: University of Michigan Press.

Light, R.L. and Warshawsky, D. (1974). "Preliminary error analysis: Russians using English", in Technical Report. National Institute of Education. USA.

Llach, M.P.A, Fontecha, A.F. \& Espinosa, S.M. (2005). "Differences in the Written Production of Young Spanish and German Learners: Evidence from Lexical Errors in a Composition", in Barcelona Language and Literature Studies, 14: 1-13.

Lupton, M. (2012). "Reclaiming the art of teaching", in Teaching in Higher Education, 18, 2: $156-66$.

Nord, C. (2005). Text Analysis in Translation, Theory, Methodology and Didactic Application of a Model for Translation-Oriented Text Analysis.Amsterdam - NewYork: Radopi B.V. 
Popović, M. (2011). "Hjerson: An Open Source Tool for Automatic Error Classification of Machine Translation Output", in The Prague Bulletin of Mathematical Linguistics, 96: 59-68.

Richards, J.C. (1971). "A non-contrastive approach to error analysis", in ELT Journal, 25, 3: 204-19.

Scrivener, J. (2005). Learning Teaching. Oxford: Macmillan Education.

Vassileva, I. (1998). "Who am I/how are we in academic writing? A contrastive analysis of authorial presence in English, German, French, Russian and Bulgarian", in International Journal of Applied Linguistics, 8, 2: 163-85.

Vizental, A. (2007). Metodica predării limbii engleze. Strategies of Teaching and Testing English as a Foreign Language. Iaşi: Polirom.

Wardhaugh, R. (1970). "The contrastive analysis hypothesis", in TESOL Quarterly, 4: 123-30.

Yang, S. and Huang, Y. (2004). "The impact of the absence of grammatical tense in L1 on the acquisition of the tense-aspect system in L2", in International Review of Applied Linguistics in Language Teaching (IRAL), 42, 1: 49-70.

Zawahreh, F.A.S. (2012). "Applied Error Analysis of Written Production of English Essays of Tenth Grade Students in Ajloun Schools", in International Journal of Learning \& Development, 2, 2: 280-99. 